\title{
ASPECTOS EDITORIAIS DA POESIA SPOKEN WORD: OS DICIONÁRIOS PARATÓPICOS DE NI BRISANT
}

\author{
Pedro Alberto Ribeiro Pinto ${ }^{1}$
}

\begin{abstract}
Resumo: Este artigo tece considerações sobre as manifestações da chamada poesia spoken word (definida, lato sensu, como "poesia falada") e dos poetry slams (batalhas de poesia) no Brasil contemporâneo, a partir da perspectiva das materialidades da cultura e dos estudos discursivos. Toma-se como objeto de análise certa produção poética do autor Ni Brisant, avançando a hipótese de que os processos envolvidos na declamação e no registro de poemas configuram-se como práticas discursivas de caráter editorial, que implicam uma gestão de textualidades e autorias em uma cultura da conexão(Jenkins, Green \& Ford, 2014).
\end{abstract}

Palavras-chave: Gestão autoral. Materialidades do literário. Mediação editorial. Poesia spoken word.

\section{EDITORIAL ASPECTS OF SPOKEN WORD POETRY: THE PARATOPIAN DICTIONARIES OF NI BRISANT}

\begin{abstract}
This article discusses contemporary instances of spoken word poetry and poetry slams in Brazil from the perspective of the materiliaty of culture and discursive studies. A certain poetic production of the author Ni Brisant is taken as an object of analysis from which we work on the hypothesis that the processes involved in the performance and in the recording of poems are configured as discursive practices of editorial character, implying a management of textualities and authorships in a networked culture (Jenkins, Green \& Ford, 2014).
\end{abstract}

Keywords: Authorship management. Materialities of Literature. Editorial mediation. Spoken word poetry.

\footnotetext{
${ }^{1}$ Bolsista CAPES em nível de Mestrado pelo Programa de Pós-Graduação em Linguística da Universidade Federal de São Carlos (PPGL/UFSCar). pedro.a.ribeiro2@gmail.com
} 


\title{
Introdução, ou A poesia como edição dos corpos
}

No segundo capítulo do seu livro Take the Mic, o poeta estadunidense Marc Kelly Smith relaciona a poesia performática tal qual praticada nos chamados poetry slams a um histórico mais amplo da prática de declamação de poemas, encontrando em contextos variados como os festivais dionisíacos de que participavam Eurípedes e Sófocles, as composições coletivas japonesas de haicais no século XV e as Justas Literarias do México dos anos 1600 não apenas elementos recorrentes no que poderíamos chamar a formulação material dos textos (cf. FLUSSER, 2007) - notadamente o uso concomitante da voz e de gestos do corpo -, mas ainda a presença de um aspecto competitivo que possibilitaria aos poetas chamar a atenção de um público mais amplo e, ao mesmo tempo, refinar sua arte (SMITH, 2009, p. 17 19).

Para além de uma "competição de poesia falada", no entanto, os slams de poesia carregariam o estatuto de eventos que consolidam circuitos e comunidades de frequentadores, tomando, segundo Roberta Estrela D'alva,

\begin{abstract}
a proporção de uma celebração, que conta com um mestre de cerimônias, chamado slammaster, e onde a palavra é comungada entre todos, sem hierarquias. Um círculo poético onde as demandas "do agora" de determinada comunidade, suas questões mais pungentes, são apresentadas, contrapostas e organizadas de acordo com suas vivências e experiências. (D’ALVA, 2014, p. 112)
\end{abstract}

No contexto do Brasil dos anos 2010, mais especificamente em São Paulo, encontramos pelo menos mais um tipo de evento de partilha de textos poéticos além dos slams. os saraus. Conforme Tennina (2013), se no século passado tais saraus eram marcados por certa necessidade de "legitimar as obras frente aos representantes da sociedade aristocrática e da intelectualidade da época" e determinado interesse em "exibir a posição de classe" (p.11), nos eventos realizados na segunda dezena do século XXI em regiões como a Zona Sul de São Paulo, em localidades como bares, ruas e praças, os participantes seriam mais propensos a conformar um "mapa afetivo", deslocando-se pelo território urbano em busca de maior dispersão de sua poesia e de experienciar a declamação da palavra. 
Essa experiência aparece parafraseada em diversas formulações nas falas dos organizadores desses eventos e dos sujeitos que deles participam, sendo o bom desempenho nas declamações de tal modo valorado que Smith (2009, p. xv) chega a chamar de sofrimento o fato de presenciar poetas que se apresentam sem expressões faciais, gestos ou entonações, comparando-os a mortos vivos saídos dos sets de filmes de terror, zumbis necessitando de meios e técnicas para voltar à vida.

Por sua vez, o poeta Ni Brisant, fundador do sarau Sobrenome Liberdade, ao ser questionado sobre as motivações do evento que organiza, coloca em relevo a declamação como uma atividade capaz de ampliar as capacidades singulares através da partilha coletiva:

O sarau não é pra criar um artista que fale em nome da periferia, que fale em nome dos outros. Mas é pra que cada pessoa encontre sua corda vocal, encontre sua expressão, encontre sua voz, cara. (...) A gente pode mais quando a gente se junta. A gente tem muito mais potência quando a gente se abraça, quando a gente é capaz de dialogar, de criar esses elos, essas conexões. (PERIFERIA INVISÍVEL, 2013, 0'56" - 1'38")

Entretanto, a despeito dessas colocações e do papel atribuído à potência, ao encontro ou à conexão proporcionados pela poesia declamada, tanto os poetas citados quanto outros adeptos da declamação de poemas trabalham com diferentes meios de dispersão de suas obras, mesmo com alguns que eventualmente não sejam orais - como livros, livretos, textos em blogs ou redes sociais - ou que, possuindo aspectos de oralidade, não se efetuam no contexto imediato da performance, mas em seu registro - como no caso de vídeos em plataformas de streaming, áudios, álbuns musicais etc ${ }^{2}$.

Essas duas modalidades - a poesia declamada "ao vivo" durante os slams e a poesia gravada e reproduzida em outras vias - diferenciariam a posição dos poetas nas comunidades artísticas, de modo que aqueles que participam dos slams são chamados de slammers, distintos daqueles que

\footnotetext{
${ }^{2}$ No caso da produção brasileira, conferir, por exemplo, os trabalhos de Akins Kintê, Bobby Baq, Giovani Baffô, Isabela Penov, Luiza Romão, Luz Ribeiro, Mariana Schoenwetter Lacava, Mel Duarte, Nelson Maca, Pedro Bomba, Renan Inquérito, Ricardo Aleixo, Roberta Estrela D’Alva, Victor Rodrigues, dentre outros.
} 
seguem carreiras solo fora das competições e que adotam uma manifestação que pode ser registrada, reproduzida e comercializada, então classificados como artistas que fazem spoken word (D'ALVA, 2014, p. 112), embora, como dito acima, exista a possibilidade de entrelaçamentos entre as modalidades.

Com esses fenômenos em vista, buscarei avançar a hipótese de que tanto os processos envolvidos no registro da poesia spoken word em formato de códice ou de registros audiviosuais quanto aqueles mobilizados na declamação ao vivo de poetas em slams e saraus configuram-se como práticas discursivas de caráter editorial, que implicam uma gestão das textualidades e das autorias. Para isso, me assentarei numa abordagem discursiva de viés enunciativo-comunicacional derivada dos estudos de Dominique Maingueneau voltados à investigação do discurso literário, focalizando a produção do supracitado poeta Ni Brisant e voltando-me de modo mais específico a um conjunto de materiais composto por uma postagem em seu blog em 2013, por um registro em vídeo de sua performance durante um slam em 2014, pelo livro Se Eu Tivesse Meu Próprio Dicionário (2014) e pelo álbum musical Algodão de Fogo (2015).

\section{Inscrever, fluir entre impossíveis}

Não são óbvias as construções epistemológicas que estabelecem as conexões entre as materialidades do literário e uma proposição da autoria como uma prática de gestão inervada a práticas editoriais. De fato, segundo a perspectiva a partir da qual o linguista francês Dominique Maingueneau (2014) propõe categorias analíticas para compreensão do literário, tal ponte só pode ser estabelecida se negamos doxas que, como aquela advinda da estética romântica, "privilegia[m] a singularidade do criador e minimiza o papel dos destinatários", ignorando os aspectos institucionais próprios da escrita literária e por vezes os tomando como "um universo hostil à criação" (2014, p.89).

Esse caráter negativo (de negação) da base propositiva de um viés discursivo para compreender o literário tem como positividade a tomada do exercício da literatura como um ato de comunicação, de modo a atribuir papeis nucleares tanto à produção quanto à recepção e à institucionalidade 
tomadas como inerentes à criação, considerando os modos pelos quais os autores inscrevem seus textos, tanto em termos de como mobilizam uma língua quanto em termos de como estes textos circulam no mundo. Para esta abordagem, são centrais as formas pelas quais os autores demonstram que são autores, os modos pelos quais eles são reconhecidos como autores e como se definem suas representações, ações e comportamentos frente às condições de autoria.

Vinculadas necessariamente a um regime de funcionamento histórico, tais condições não podem ser tomadas como invariantes ou imutáveis, seja em termos diacrônicos, ao longo de uma linha cronológica determinada, seja em termos de uma atualização sincrônica. Nó complexo, a autoria se tece conjunturalmente, de modo a se definir não apenas pela distribuição dos textos em termos sócio-espaciais - podem ser distintas, por exemplo, as condições gerais dos processos autorais em variadas escalas discursivo-geográficas -, mas também por aquilo que se escreve: o autor será, então, um autor de poemas, ou de artigos científicos de física nuclear, ou de romances, ou de um estudo de caso em linguística aplicada, ou de um artigo sobre música etc. (SALGADO, 2017, p. 125 - 126).

No caso da produção de slammers e de artistas spoken word colocados como uma espécie de par no funcionamento de certa produção poética, como esboçamos na introdução -, temos um atravessamento contínuo não apenas de uma modalidade sobre a outra, mas também atravessamentos das diversas comunidades existentes e do fato dos slams partilharem uma origem fortemente marcada: segundo certa historiografia consagrada entre os participantes desses eventos, todos os slams derivariam daqueles realizados no bar Green Mill desde 1986 com organização de Marc Kelly Smith e, mesmo quando ressaltadas as singularidades de cada comunidade, toma-se essa origem como balizadora e como permissiva dessas singularidades:

as comunidades de slam organizam-se de acordo com suas realidades e são incentivadas, pelo próprio fundador Marc Smith, a levarem em consideração suas especificidades e a criarem dinâmicas de funcionamento que atendam às suas demandas, para que a prática do slam se torne orgânica e não algo rígido e aprisionador. $\mathrm{O}$ 


\begin{abstract}
slam tem um caráter copyleft, nenhuma das comunidades paga para usar o nome ou o "método", as informações são disponibilizadas em rede para todos e incentivados o diálogo e o trânsito entre diferentes comunidades. (D'ALVA, 2014, p. 113, grifos originais)
\end{abstract}

Vale ressaltar, a partir do trecho acima, que se os slams adotam um caráter copyleft de funcionamento, em oposição a uma configuração de copyrights (direitos autorais), o mesmo não se aplica necessariamente a todas as produções spoken word, que muitas vezes têm o intuito de circular comercialmente e buscam registros jurídicos, de patente e autoria. Esta decisão - a de cobrar ou não um valor monetário por uma textualidade configura-se como um dos muitos aspectos de ordem editorial relativos à circulação desse material: se consideramos, com Chartier (2007, p. 12), os “diversos momentos, técnicas e intervenções" pelos quais os textos passam em sua produção, podemos observar uma série de outras decisões e estratégias às quais os sujeitos são constantemente chamados a recorrer para levar a público - com mais ou menos êxito, com maior ou menor autonomia um texto "final", em vias de ser distribuído para uma comunidade leitora.

A despeito das especificidades desses momentos, técnicas e intervenções, podemos afirmar que todas essas categorias são desempenhadas em uma etapa de constituição autoral dos textos. Isto não equivale a afirmar que as eventuais figuras relacionadas ao direcionamento e à gestão dessas práticas (como capistas, revisores, editores, ou mesmo slammasters) deveriam ser entendidas necessariamente como autoras de um texto sobre o qual trabalham, mas antes que há na autoria uma instância fundamental de trabalho inscricional (MAINGUENEAU, 2014, p. 134-138), em que materialidades linguísticas e não-linguísticas cravam-se mutuamente para configurar um dispositivo comunicacional e sobre a qual agem variados sujeitos.

Este aspecto inscricional não pode ser tomado de maneira isolada dos demais aspectos constitutivos da autoria, de modo que "não se podem dissociar as operações enunciativas mediante as quais se institui o discurso e o modo de organização institucional que ao mesmo tempo o pressupõe e estrutura" (MAINGUENEAU, 2014, p. 135). Assim, todo processo de construção 
de um autor implica não apenas uma instância inscritor, mas ainda uma instância pessoa e escritor: grosso modo, a primeira aponta para a existência de um ser no mundo, designado em uma série de termos como uma idade, um tipo de família, uma profissão e uma série de outros tropismos que indiciam uma vida; por sua vez, a segunda designa uma dimensão pública do trabalho inscricional, em que os textos são efetivamente atribuídas a alguém - estão aí as resenhas, as entrevistas, os prêmios, as feiras, os editais etc.

É a partir do entrelaçamento dessas instâncias que se expressam as relações identitárias, espaciais e temporais atuantes nos processos de subjetivação dos sujeitos-autores, sempre posicionados de modo ambíguo em relação ao espaço social: se não é verdade que a produção literária seja incompatível com outras atividades da vida "ordinária", também não se pode negar seu caráter de "excesso" e de deslocamento das realidades. Por isso, podemos afirmar que as instâncias pessoa, escritore inscritor conformam um nó borromeano cujas propriedades apontam para a paradoxal pertença dos escritores nas sociedades - pertença paratópica, que encontra nas frestas da vida corriqueira a possibilidade de emergir, mesmo que para negar a vida de que emerge.

Estes fenômenos exploram os limiares daquilo que temos chamado de espaço canônico e espaço associado. o primeiro circunscreve as produções advindas de um regime delocutivo do dizer, em que o autor "se oculta diante dos mundos que instaura" (MUSSALIM, 2012, p. 954) - confunde-se, portanto, com as próprias manifestações autorais tomadas efetivamente como a "obra" de um autor. O segundo, por sua vez, pode ser compreendido como o conjunto de textualidades que se realizam em um regime elocutivo, acompanhando as produções do espaço canônico: trata-se, por exemplo, das dedicatórias, dos prefácios, das entrevistas, das resenhas, das cartas, dos debates etc (MUSSALIM, 2012, p. 955).

Note-se que as colocações acerca do "espaço canônico" que se interliga à figura de um autor nos permitem pensar em uma série de objetos para além de um livro impresso. Isso pode soar particularmente pungente num período técnico-científico-informacional em que muito se discute as "novas relações espaço-temporais que as tecnologias da informação e da comunicação animam" (SALGADO, 2016a, p. 193) e em que a existência de 
versões digitais das obras em formatos como o Portable Document Format (.pdff e de aparelhos específicos para a leitura de e-books estão na ordem do ordinário para diversas comunidades, mas tal conceito também possibilita pensarmos numa série de outras materialidades que escapam à natureza escrita e à organização própria dos códices, como aqueles que citei anteriormente (audiobooks, álbuns musicais, plataformas como o YouTube e a própria declamação de poemas), uma vez que essas materialidades podem constituir e dar a ver o literário: a maneira como um texto se inscreve materialmente relaciona-se diretamente com a produção de seus sentidos.

\section{Se Ni Brisant tivesse seu próprio dicionário}

Em relação às atuais condições culturais e de mercado relacionadas à difusão de textos por um conjunto de mídiuns ${ }^{3}$ variados, Jenkins, Green e Ford (2014) destacam a tendência de consolidação de uma cultura da conexão cujos princípios se oporiam à tradicional difusão dos modelos de negócios pautados na radiodifusão e na centralização das informações. Dentre os aspectos que definiriam os paradigmas de tal cultura, destaca-se a veiculação de textos que "vários públicos possam espalhar por diferentes motivos", de modo que os consumidores deste texto possam "moldar o contexto do material conforme o compartilham no âmbito de suas redes sociais" (JENKINS, GREEN \& FORD, 2014, p. 29)

Esses mídiuns não atuam de forma isolada, mas antes remetem um ao outro através de compartilhamentos de conteúdo, remissão por hyperlinks, menção ao nome das páginas durante performances, link das páginas em livros etc. Isso não significa, entretanto, que a migração dos textos de um mídium a outro seja uma mera transposição: de fato, conforme verificamos anteriormente, a própria mudança de canal implica a

\footnotetext{
${ }^{3}$ Ainda que o termo "mídium" seja mobilizado por Maingueneau no interior das teorias discursivas, sendo "mídia" a terminologia adotada por Jenkins, Green e Ford, optei - por minha conta e risco - por utilizar mídium aqui, uma vez que a definição ampla dessa noção me parece compatível com a proposta geral dos estudos comunicacionais empreendidos pelos pesquisadores estadunidenses: "Para tornar pensável o surgimento de uma obra, sua relação com o mundo no qual surge, não podemos separá-la de seus modos de transmissão e de suas redes de comunicação. (...) A transmissão do texto não vem depois de sua produção; a maneira como o texto se institui materialmente é parte integrante do seu sentido" (MAINGUENEAU, 2014, p. 212). No entanto, as relações, proximidades e diferenças entre os conceitos ainda parecem carecer de uma investigação mais profunda e uma definição sistemática.
} 
constituição de diferentes efeitos e também uma necessidade por novas decisões frente ao material veiculado.

A produção poética de $\mathrm{Ni}$ Brisant parece emblemática dessa tendência, uma vez que observamos o conjunto de canais que o poeta tem mobilizado para difundir seus materiais. Além de criar páginas "oficiais" na rede social Facebook para cada um de seus livros, o autor ainda mobiliza outros meios de dispersão que poderíamos chamar de "analógicos", como a colagem de lambes-lambes em postes de luz, a criação de um sebo itinerante em uma bicicleta ou a participação em saraus como meios de dar a ver sua produção $0^{4}$

Tomemos um caso: em uma postagem em seu blog no dia 7 de novembro de 2013, intitulada "se eu tivesse meu próprio dicionário" (caixa baixa no original), o poeta divulgava uma lista de 25 palavras em caixa alta seguidas de uma breve definição com menos de 140 caracteres. As palavras eram ordenadas em uma ordem alfabética linear em termos de sua primeira letra ("Água" antes de "Boxe"), mas na ordem contrária em termo da segunda letra em diante ("Sorvete" antes de "Saudade"):

\begin{tabular}{|l|l|l|l|l|}
\hline Água & Fardas & K & Ócio & Vento \\
\hline Boxe & Garoa & Lobisomem & Pódio & Whisky \\
\hline Bahia & Horas & Montanha & Riacho & Xadrez \\
\hline Ciúmes & Inverno & Mãe & Sorvete & Yes \\
\hline Doutor & Jardim & Navio & Saudade & Zero \\
\hline
\end{tabular}

Tabela 1 - Poemas veiculados na postagem do dia 7 nov. 2013 (cf. BRISANT, 2013)

Tempos depois, no dia 27 de agosto de 2014, o perfil de usuário no YouTube "Jessika Martins" postou um vídeo intitulado "Slam do Corpo: Ni Brisant - XI (18/06/2014)", em que vemos o poeta declamar sete dos vinte e cinco poemas-verbetes listados acima. Os poemas são acompanhados por uma tradução simultânea da língua portuguesa para LIBRAS e, segundo a

\footnotetext{
${ }^{4}$ Em termos das redes sociais utilizadas por Ni Brisant para veicular seu trabalho, pude contabilizar (em abril de 2017) pelo menos 8 páginas administradas por ele no Facebook, 1 blog na plataforma Blogger, 1 perfil no Twitter, 1 perfil no Instagram e 1 perfil no YouTube, fora páginas de terceiros que veiculam constantemente seu material.
} 
descrição do vídeo, fizeram parte da participação de Ni Brisant durante a realização do Slam do Corpo, realizado no dia 18 de junho de 2014 no SESC Pinheiros, em São Paulo. Além dos sete poemas que já constavam na postagem do ano anterior (Água / Vento / Jardim / Garoa / Mãe / Whisky / Navio), são acrescentados outros 12, apresentados em uma ordem que foge à alfabética:

\begin{tabular}{|l|l|l|l|l|}
\hline Água & Poesia & Jardim & Whisky & Horizonte \\
\hline Abraço & Óculos & Garoa & Cachaça & Retirante \\
\hline Sonho da Valsa & Amor & Sorriso & Travesti & \multirow{2}{*}{} \\
\cline { 1 - 3 } Vento & Felicidade & Mãe & Navio & \\
\cline { 1 - 3 } & & &
\end{tabular}

Tabela 2 - Poemas declamados por Ni Brisant durante o Slam do Corpono dia 18 jun. 2014 (cf. MARTINS, 2014)

O número reduzido de poemas declamados pode ser relacionado a uma das regras do slam - o limite de 3 minutos para cada apresentação, mas para além da presença de poemas que não constavam na postagem do blog, podemos notar modificações em alguns dos que já haviam sido veiculados, que se expandem quando da declamação no slam, como no caso do poema "Mãe":

\begin{tabular}{|c|c|}
\hline \multicolumn{2}{|l|}{ Mãe } \\
\hline Data de Circulação & Atualização do Poema \\
\hline Novembro de 2013 & Reticências, só por garantia de nunca acabar. \\
\hline Junho de 2014 & $\begin{array}{l}\text { Reticências só por garantia de nunca acabar } \\
\text { nem precisar de palavra que explique. Ficaria } \\
\text { ali ao pé da página pra gente nunca esquecer } \\
\text { que é raiz. }\end{array}$ \\
\hline
\end{tabular}

Tabela 3 - Diferenças do poema "mãe" na postagem do blog (nov. 2013) e na declamação no Slam do Corpo(jun. 2014)

Já no final desse mesmo ano, no dia 9 de novembro de 2014, o poeta publicava em seu blog uma postagem de título "VAMOS LIVRAR" (em caixa alta), em que divulgava a pré-venda de seu novo livro, Se eu tivesse meu próprio dicionário, descrito como “o menor dicionário das galáxias”, que 
conteria "78 poemas curtíssimos" cuja pretensão seria "o lindo absurdo que é mudar o significado das palavras e do mundo (por que não?)”. Segundo o autor, a publicação do livro seria feita de forma independente e comercializada a R\$14,99 pelo portal LiteraRUA, cujo foco de vendas é indiciado nas subcategorias de livros veiculados: "hip-hop", "rap", "DJ", "graffiti”, “break”, “realidade”, “poesia”, dentre outras.

Com $10 \mathrm{~cm}$ de largura, 5,6 cm de altura e projeto gráfico de Marciano Ventura, a "edição zero" de Se eu tivesse meu próprio dicionário traz uma capa assinada pelo artista plástico Célio Luigi, em que podemos ver a ilustração de uma criança vestindo um vestido de cor verde e sandálias ao mesmo tempo em que carrega um fósforo aceso na mão direita e o que parece ser uma caixa de fósforos na mão esquerda, estampada com o desenho de uma caveira. Logo acima da ilustração, em um fundo laranja com pouca saturação, lemos o título do livro em caixa alta e fonte sem serifa, alternando entre as cores vermelho e branco. Na parte de baixo da capa, no canto inferior direito e sobre um fundo azul, lê-se em branco o nome do autor.

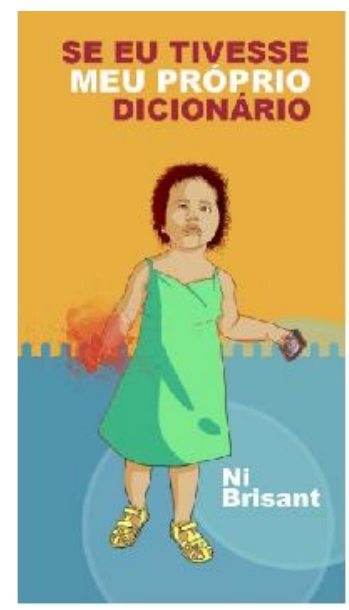

Figura 1 - Capa do livro Se eu tivesse meu próprio dicionário (cf. BRISANT, 2014)

Essa composição específica - que poderíamos dizer cenográfica (cf. MAINGUENEAU, 2014, p. 252) - não apenas indica uma chave de leitura e um tom aos poemas, como também remete a um corpo enunciador, a um processo interativo de influência sobre o leitor em que se visa constituir uma imagem do autor por meio do discurso (idem, p. 269). Esse processo fica particularmente em destaque quando comparamos a capa do livro com àquela 
do álbum musical Algodão de Fogo, lançado por Ni Brisant em 2016, que apresenta em sua capa a figura de um rapaz negro vestindo uma coroa, apresentando ainda a simbologia de corrente e de um coração perfurado por uma adaga, em tonalidades de cores pouco saturadas, em marrom, branco, preto, cinza e azul.

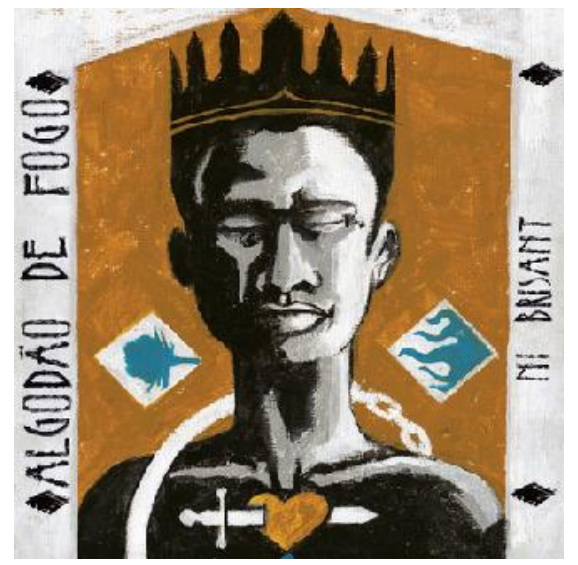

Figura 2 - Capa do álbum musical Algodão de Fogo (cf. BRISANT, 2015)

No caso do álbum musical, esse processo de atribuição de um corpo ao discurso é particularmente reforçado pela conjunção da voz do poeta com os variados fundos musicais que compõem as 10 fixas do álbum. Dentre elas, “Se eu tivesse meu próprio dicionário", apresenta 27 dos 78 micro poemas contidos no livro em 4 minutos e 24 segundos de duração. Embora só possamos ouvi-lo, podemos imaginar certa movimentação de seu corpo, evocada não apenas pela própria instrumentalização que o acompanha, mas também pelas inflexões que impõe em determinadas passagens pelos risos que manifesta ao declamar alguns dos poemas. Para um ouvinte que não teve um contato prévio com a produção do autor, a faixa toda poderia até mesmo ser considerada um único poema, conclusão certamente plausível.

Se comparamos a seleção de poemas apresentada no álbum musical com a seleção das demais formalizações que citamos até aqui, notamos que sete poemas compõem todas as atualizações desse material, enquanto os outros se repetem em 2 ou 3 dessas materialidades, sendo o livro a atualização mais abrangente em termos de variedade dos verbetes, com apenas 1 poema ocorrendo em outra manifestação sem estar no livro (poema "Sorriso", declamado no Slam do Corpo): 
ASPECTOS EDITORIAIS DA POESIA SPOKEN WORD: OS DICIONÁRIOS PARATÓPICOS DE NI BRISANT

\begin{tabular}{|c|c|c|c|c|c|}
\hline \multicolumn{3}{|c|}{ Se eu tivesse meu próprio dicionário } & \multirow{2}{*}{$\begin{array}{l}\begin{array}{l}\text { Postagem } \\
\text { no Blog }\end{array} \\
\text { Água }\end{array}$} & \multirow{2}{*}{$\begin{array}{l}\begin{array}{l}\text { Slam do } \\
\text { Corpo }\end{array} \\
\text { Água }\end{array}$} & \multirow{2}{*}{$\begin{array}{l}\text { Algodão de Fogo } \\
\text { Água }\end{array}$} \\
\hline Abraço & Fome & Pódio & & & \\
\hline Água & Forró & Poesia & Boxe & Abraço & Bahia \\
\hline Amigo & Garoa & Poeta & Bahia & Forró & Ciúmes \\
\hline Amor & Goleiro & Quadril & Ciúmes & Vento & Divórcio \\
\hline Aspas & Graça & Retirante & Doutor & Poesia & Doutor \\
\hline Bahia & Gratidão & Riacho & Farda & Óculos & Engarrafamento \\
\hline Boxe & Herói & Saudade & Garoa & Amor & Felicidade \\
\hline Brincar & Horas & Solidão & Horas & Felicidade & Filho \\
\hline Cachaça & Horizonte & Sombra & Inverno & Jardim & Forró \\
\hline Canibal & Inferno & Sorvete & Jardim & Garoa & Garoa \\
\hline Canos & Introspecção & Teletransporte & K & Sorriso & Jardim \\
\hline Ciúmes & Inverno & Torneira & Lobisomem & Mãe & Goleiro \\
\hline Corda & Jardim & Travesti & Montanha & Whisky & Horizonte \\
\hline Cumprimento & $\mathrm{K}$ & Umbigo & Mãe & Cachaça & Inverno \\
\hline Dentro & Lobisomem & Utopia & Navio & Travesti & Inferno \\
\hline Desperdício & Mãe & Último & Ócio & Navio & Montanha \\
\hline Dinheiro & Mentira & Vento & Pódio & Horizonte & Mãe \\
\hline Divórcio & Montanha & Vírgula & Riacho & Retirante & Navio \\
\hline Doutor & Morte & Whisky & Sorvete & & Natal \\
\hline Encantado & Natal & Xadrez & Saudade & & Ócio \\
\hline Engarrafamento & Navio & Yes & Vento & & Óculos \\
\hline Espanto & Nunca & Zelo & Whisky & & Pódio \\
\hline Eternidade & Ócio & Zero & Xadrez & & Vento \\
\hline Farda & Óculos & & Yes & & Poesia \\
\hline Felicidade & Paradoxo & & Zero & & Travesti \\
\hline Filho & Parque & & & & Whisky \\
\hline & & & & & Yes \\
\hline
\end{tabular}

\begin{tabular}{|l|}
\hline \\
\hline
\end{tabular}

O poema circulou em 4 dos 4 materiais O poema circulou em 3 dos 4 materiais O poema circulou em 2 dos 4 materiais O poema circulou em 1 dos 4 materiais

Tabela 4 - Quadro comparativo da seleção dos poemas no livro (2014), na postagem do blog (2013), no slam (2014) e no álbum musical (2015) 
Mesmo entre as duas formalizações de Se eu tivesse meu próprio dicionário aqui recortadas que possuem aspectos vocalizados - a performance no slam e a faixa musical de Algodão de Fogo-, são notáveis as diferenças prosódicas e o fato de que enquanto uma é acompanhada por uma tradução simultânea em LIBRAS e registra reações da plateia, a outra justapõe a performance vocal de Brisant a um fundo musical, sem que possamos afirmar se é a faixa musical que está acompanhado sua interpretação, ou o contrário.

Podemos analisar algumas dessas diferenças a partir das categorias analíticas propostas por Silva (2016, p.160-163) a partir dos trabalhos de Whitmore, utilizadas para descrever o funcionamento do sistema vocal em uma performance poética, de modo a focalizar cada uma das características que formalizam um ato comunicacional. São essas categorias: (1) intensidade; (2) altura; (3) inflexão; (4) ressonância; (5) articulação (6) tempo; (7) ritmo; (8) língua; (9) ação; (10) modo de falar; (11) projeção vocal; (12) consciência vocal; (13) focalização vocal; (14) energia vocal; (15) manutenção vocal.

Em uma análise dessa natureza, cada categoria é disposta em uma linha de uma tabela, de modo que então

\begin{abstract}
cada um destes elementos é analisado individualmente. Jon Whitmore preconiza a utilização de escalas para medir cada uma das características da voz. E a representação gráfica de cada escala numa linha, cujos extremos são os opostos do elemento em análise (por exemplo, em relação à intensidade, numa ponta temos silêncio, na outra fortissimo), e onde a performance em análise se situa algures num ponto dessa linha. (SILVA, 2016, p. 160)
\end{abstract}

Silva exemplifica o preenchimento da categoria "ação", relativa à realização ou não realização da palavra dita em voz alta acompanhada por gestualidades, de modo que em uma das pontas teríamos "apenas palavras" e do outro "nenhuma palavra". A partir do preenchimento dessa linha, podemos definir as ações de "ler", “dizer" e "interpretar" com base em seu posicionamento na categoria em questão: 
ASPECTOS EDITORIAIS DA POESIA SPOKEN WORD: OS DICIONÁRIOS PARATÓPICOS DE NI BRISANT

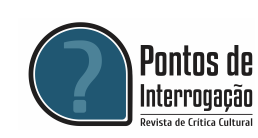

\begin{tabular}{|l|l|l|l|}
\hline Ação & Apenas palavra & $\begin{array}{l}\text {--- ler ---- dizer ----- interpretar ---- } \\
\text {--------- }\end{array}$ & $\begin{array}{l}\text { Nenhuma } \\
\text { palavra }\end{array}$ \\
\hline
\end{tabular}

Tabela 5 - Exemplificação de preenchimento da categoria “ação” (cf. SILVA, 2016, p.

162)

Ainda que essas escalas não possam ser consideradas em termos absolutos (o fato de um analista julgar uma performance mais próxima do extremo nenhuma palavra não garante que outro analista assim a julgaria, por exemplo), elas podem ser melhor utilizadas em termos comparativos, possibilitando a um analista demonstrar eventuais diferenças entre dois registros de um mesmo poema, por exemplo. No caso das formalizações de $S e$ eu tivesse meu próprio dicionário durante o Slam do Corpo e durante a faixa contida em Algodão de Fogo, poderíamos descrever, por exemplo, suas diferenças em termos de inflexões (mudanças da altura da voz), ritmos (alternância ordenada dos elementos vocais), articulações (propriedades ligadas à percepção de uma pronúncia como sendo "clara" ou "arrastada) e mesmo as próprias ações:

\begin{tabular}{|l|l|l|l|}
\hline Inflexão \\
\hline Slam do Corpo & Sem inflexões & -------X--------- & Falar cantado \\
\hline Algodão de Fogo & Sem inflexões & -----------X----- & Falar cantado \\
\hline
\end{tabular}

\begin{tabular}{|l|l|l|l|}
\hline \multicolumn{2}{|l|}{ Ritmo } \\
\hline Slam do Corpo & Sem mudança & $-------X---------$ & Sempre alterado \\
\hline Algodão de Fogo & Sem mudança & $------------X----$ & Sempre alterado \\
\hline
\end{tabular}

\begin{tabular}{|l|l|l|l|}
\hline \multicolumn{2}{|l|}{ Articulação } & \multicolumn{3}{l|}{} \\
\hline Slam do Corpo & Imperceptível & $------\mathrm{X}------------$ & Clara \\
\hline Algodão de Fogo & Imperceptível & $-------------x----$ & Clara \\
\hline
\end{tabular}

\begin{tabular}{|l|l|l|l|}
\hline Ação \\
\hline Slam do Corpo & Apenas palavra & ---------X-------- & Nenhuma palavra \\
\hline Algodão de Fogo & Apenas palavra & ----X------------- & Nenhuma palavra \\
\hline
\end{tabular}

Tabela 6 - Quadros comparativos entre a declamação de Ni Brisant durante o Slam do Corpo e o álbum musical Algodão de Fogo 
Todas essas variações - na seleção dos poemas, em suas extensões, das imagens que os acompanham e de suas realizações prosódicas configuram-se como práticas editoriais com efeitos diretamente ligados a modos específicos de gestão de uma autoria, na medida em que propõem determinados caminhos para suas leituras possíveis, de modo que cada palavra é “organizada para materializar o que não está presente e que o poeta deseja presentificar para o público" (D’ALVA, 2014, p. 115).

Há nessas escolhas, portanto, não apenas o estabelecimento do trabalho de um inscritor que mobiliza os variados recursos de formalização das textualidades, mas ainda uma forte marcação de uma pessoa cuja existência no mundo não se desvincula de sua produção autoral e da instância escritor que também compõe sua autoria, não apenas propondo às comunidades leitoras certos gestos de interpretação, mas também gerindo as condições de autor responsável pelos materiais que carregam seu nome, sejam essas textualidades as produções "oficiais" estabelecidas em seu espaço canônico, sejam elas registros feitos por terceiros a partir de leituras públicas e declamações (como no caso da gravação do Slam do Corpo), registros cuja existência e circulação escapam ao seu total controle.

\section{Alguns apontamentos (ou: Dizer, Registrar, Convergir)}

Logo nas primeiras páginas de sua Introdução à Poesia Oral, cuja primeira edição data de 1983, Paul Zumthor declara falsa toda oralidade que "apenas verbalize uma escrita", uma vez que, guiada por um sistema de escrita, as textualidades vocalizadas perderiam sua capacidade de divagação, marca da fuga da voz às intenções ou aos conteúdos pré-programados dos discursos (ZUMTHOR, 2010, p. 12). No entanto, levada às últimas consequências e recolocada perante as atuais condições de produção dos dizeres em comunidades atravessadas pelos fenômenos da cultura $d a$ conexão de que falam Jenkins, Green e Ford (2014), essa afirmação não apenas omite o fato de que oralidade e escrita se sobrepõem continuamente sobreposição que se faz mais fortemente visível no caso dos dispositivos de comunicação multimodal -, mas também subestima os efeitos causados pela 
vocalização de uma escrita e ignora as consequências dos registros sobre as proposições teóricas a respeito da oralidade.

De fato, ainda que ao longo desse artigo tenha-se elaborado uma espécie de historiografia de alguns poemas do poeta Ni Brisant, mostrando algumas de suas variações ao longo de uma linha cronológica, todas as formulações apresentadas, ao menos até a data de escrita de artigo, convivem e conectam-se entre si na WWW num mesmo instante, o agora. Assim, ainda que cada uma das atualizações dos textos apresentados mobilize diferentes técnicas e normas para sua constituição inscricional num nível mais imediato, nenhuma delas pode ser tomada como "a verdadeira versão final", sobretudo se adotamos a perspectiva de sua circulação por diferentes comunidades leitoras e a própria experiência de um leitor ao tomar o primeiro contato com cada um dos textos.

O próprio ato de recolocar um texto em circulação (seja de maneia impressa, verbalizada ou em dispositivos digitais) exige a tomada de uma série de decisões:

Nessa cultura conectada em rede, não podemos identificar uma causa isolada que leve as pessoas a propagar informações. As pessoas tomam uma série de decisões de base social quando escolhem difundir algum texto na mídia: vale a pena se engajar nesse conteúdo? Vale a pena compartilhar? É de interesse para algumas pessoas específicas? Comunica algo sobre mim ou sobre meu relacionamento com essas pessoas? Qual é a melhor plataforma para espalhar essa informação? Será que deve circular com uma mensagem especial anexada? Mas, se nenhum comentário adicional é anexado, simplesmente receber uma história ou um vídeo de alguém insere todo um leque de novos e possíveis significados ao texto. Quando uma pessoa ouve, lê ou vê conteúdos compartilhados, ela pensa não apenas - e muitas vezes nem principalmente - no que os produtores podem ter desejado dizer com aquele material, mas no que estava tentando lhe comunicar quem o compartilhou com ela. (JENKINS, GREEN \& FORD, 2014, p. 37)

Nesse sentido, ao tomarmos como corpus de investigação objetos advindos das chamadas manifestações de poetry slams e da poesia spoken 
word, não somente contribuímos para a compreensão de práticas editoriais muitas vezes silenciadas ao longo da História, mas também apontamos para a reconsideração de certas noções e procedimentos teórico-metodológicos mobilizados para a compreensão da própria oralidade e dos fenômenos literários. No centro dessas reconsiderações parecem estar não apenas os próprios conceitos de "fala" e "literatura", já tomados como objeto de discussões polêmicas em uma imensa variedade trabalhos, mas também de conceitos mais estritos como os de espaço canônico e espaço associado, na medida em que a emergência de diferentes possibilidades tanto de interação entre escritores e leitores quanto da partilha de textos complexificam as zonas limítrofes entre o que poderíamos designar como sendo uma enunciação de ordem literária ou como uma produção que fala sobre uma.

\section{Referências}

BRISANT, Ni. Se eu tivesse meu próprio dicionário. São Paulo, 7 nov 2013. Disponível em: <http://nibrisant.blogspot.com.br/2013/11/se-eu-tivesse-meuproprio-dicionario.html>. Acesso em: 30 abr. 2017.

BRISANT, Ni. Se eu tivesse meu próprio dicionário. São Paulo: edição do autor, 2014.

BRISANT, Ni. Algodão de Fogo(CD). Brasil: Produção independente, 2015.

CHARTIER, Roger. Inscrever e apagar - cultura escrita e literatura (séculos XI - XVIII). São Paulo: EdUNESP, 2007.

D’ALVA, Roberta Estrela. Teatro Hip-Hop: a performance poética do ator-MC. São Paulo: Perspectiva, 2014.

FLUSSER, Vilém. O mundo codificado: por uma filosofia do design e da comunicação. Rafael Cardoso (Org.). Trad. Raquel Abi-Sâmara. São Paulo: Cosac Naify, 2007.

JENKINS, Henry; GREEN, Joshua; FORD, Sam . Cultura da Conexão. criando valor e significado por meio da mídia propagável. São Paulo: Aleph, 2014

MAINGUENEAU, Dominique. Discurso Literário. 2. ed. São Paulo: Contexto, 2014. 
MARTINS, Jessika. Slam do Corpo: Ni Brisant - XI (18/06/2014). YouTube, 27 ago. 2014. Disponível em: <https://www.youtube.com/watch?v=tWtaYX7-kw>. Acesso em: 30 abr. 2017.

MUSSALIM, Fernanda. Tendências em Análise do Discurso: objetos e conceitos. In: Estudos Linguísticos, São Paulo, 41 (3), p. 948-958, set-dez. 2012.

PERIFERIA INVISÍVEL. Certo Olhar com Ni Brisant - Periferia Invisível - HD. YouTube, 31 mai. 2013. Disponível em: <https://www.youtube.com/watch?v =0m4IMZBwGKs>. Acesso em: 30 abr. 2017.

SALGADO, Luciana Salazar. Quem mexeu no meu texto? Questões contemporâneas de edição, preparação e revisão textual. Divinópolis: Gulliver Editora, 2017.

SILVA, José António Geraldo Marques da. Registos sonoros de interpretação poética: análise dos modos de dizer poesia em Portugal, a partir das gravações em disco. Coimbra, 2016, [s.n.]. Tese de doutoramento. Disponível em: <http://hdl.handle. net/10316/29348>. Acesso em: 15 abr. 2017.

SMITH, Marc Kelly (2009). Take the Mic. The Art of Performance Poetry, Slam and the Spoken Word. Naperville, Illinois: Sourcebooks MediaFusion.

TENNINA, Lucía. Saraus das periferias de São Paulo: poesia entre tragos, silêncios e aplausos. In: est. lit. bras. contemp., Brasília, n. 42, p. 11-28, 2013. Disponível em: <http://periodicos.unb.br/index.php/estudos/article/ view/9989>. Acesso em: 30 de abr. 2017.

ZUMTHOR, Paul. Introdução à poesia oral. Belo Horizonte: EdUFMG, 2010.

Recebido em 30 de abril de 2017

Aceito em 07 de junho de 2017. 